\title{
Multiple consecutive norovirus infections in the first 2 years of life
}

\author{
Vesna Blazevic $^{1}$ - Maria Malm ${ }^{1}$ - Marjo Salminen ${ }^{1} \cdot$ Sami Oikarinen $^{2} \cdot$ Heikki Hyöty ${ }^{2,3}$. \\ Riitta Veijola ${ }^{4}$ Timo Vesikari ${ }^{1}$
}

Received: 10 April 2015 /Revised: 31 May 2015 / Accepted: 26 June 2015 / Published online: 9 July 2015

(C) The Author(s) 2015. This article is published with open access at Springerlink.com

\begin{abstract}
Studies investigating the magnitude and breath of protective immune responses after primary and subsequent norovirus infections in pediatric populations are limited. We investigated incidence of norovirus infections and serological responses in a child from longitudinal stool and serum samples collected from birth to 2 years of age. Four consecutive infections with distinct genotypes of norovirus were detected.
\end{abstract}

Communicated by David Nadal

Vesna Blazevic

vesna.blazevic@uta.fi

Maria Malm

maria.malm@uta.fi

Marjo Salminen

marjo.t.salminen@uta.fi

Sami Oikarinen

sami.oikarinen@uta.fi

Heikki Hyöty

heikki.hyoty@uta.fi

Riitta Veijola

riitta.veijola@oulu.fi

Timo Vesikari

timo.vesikari@uta.fi

1 Vaccine Research Center, University of Tampere Medical School, Biokatu 10, FI-33520 Tampere, Finland

2 Department of Virology, University of Tampere Medical School, Tampere, Finland

3 Fimlab Laboratories, Pirkanmaa Hospital District, Tampere, Finland

4 Department of Pediatrics, Medical Research Center, University of Oulu, Oulu, Finland
Serum antibodies were genotype-specific offering no protection to reinfection with heterologous virus.

Conclusion: This study describes norovirus-specific serological responses in a child with four consecutive norovirus infection during the first 2 years of life. The response is typespecific and does not protect from a subsequent infection with a heterologous virus.

What is Known:

- Correlates of protection to norovirus infection and disease are not yet determined, and most of the presently available data concern adult population.

What is New:

- This manuscript describes serological immune responses after primary and subsequent infections in a child during the first 2 years of life.

Keywords Norovirus $\cdot$ Infant $\cdot$ Immunity $\cdot$ Infections $\cdot$ Serology

$\begin{array}{ll}\text { Abbreviations } \\ \text { DIPP } & \text { Type 1 diabetes prediction and prevention } \\ \text { ELISA } & \text { Enzyme-linked immunosorbent assay } \\ \text { G } & \text { Genogroup } \\ \text { HBGA } & \text { Histo-blood group antigens } \\ \text { HRP } & \text { Horseradish peroxidase } \\ \text { IgG } & \text { Immunoglobulin G } \\ \text { NoV } & \text { Norovirus } \\ \text { OD } & \text { Optical density } \\ \text { OPD } & o \text {-Phenylenediamine dihydrochloride } \\ \text { ORF } & \text { Open reading frame } \\ \text { PBS } & \text { Phosphate-buffered saline } \\ \text { RT-PCR } & \text { Reverse transcription polymerase chain reaction } \\ \text { VLP } & \text { Virus-like particle }\end{array}$




\section{Introduction}

Noroviruses (NoVs) cause great burden of acute gastroenteritis worldwide in children under 5 years of age with approximately 200,000 deaths annually [1]. The virus is genetically highly diverse with more than 30 genotypes belonging to six genogroups (GI-GVI) [2]. NoV infections in children are associated with GI and GII, with genotype GII.4 being predominant for a long period of time [2]. These infections are acquired early in life, and there is limited knowledge on protective immune responses and duration of protection in natural infection in children. A longitudinal study of NoV infection in young children has recently demonstrated that reinfections with distinct genotypes commonly happen $[3,4]$, but the immunity was not directly measured. In a recent case report [5], NoV-specific mucosal antibodies did not protect a child from re-infection with heterologous NoV. In here, we report a child followed from birth to 2 years of age with four NoV infections and emergence of acquired NoV-specific serum IgG and blocking antibodies. NoVspecific serum antibodies, which block binding of NoV capsid-derived virus-like particles (VLPs) to the host cell attachment factors, histo-blood group antigens (HBGAs), are considered as correlates of protection to NoV infection [6].

\section{Materials and methods}

A healthy newborn was recruited in 2001 into the prospective Type 1 Diabetes Prediction and Prevention (DIPP) Study starting at birth [7]. The study was approved by the ethics committee of the University of Oulu and Oulu University Hospital and a written informed consent was obtained from the parents. Serum samples were collected at 0 (cord blood), 3, $6,12,18$, and 25 months of age, and stool samples were collected monthly from 4 to 19 months of age (Table 1).

Reverse transcription-PCR (RT-PCR) and ORF1 polymerase (region A) sequencing were used for detecting NoV genotype from stool suspensions according to the well-established methods [8]. NoV GI.3 and GII.4 VLPs cloned from original patient sequences from 2002 (GI.3, GenBank reference strain accession no. AF414403) and 1999 (GII.4, AF080551) were produced in baculovirus-insect cell expression system as earlier described [9]. These VLPs were chosen as antigens to detect NoV GI- and GII-specific IgG antibody responses using an ELISA method [10] as these sequences originated near the time of serum collections in this study (2001-2003, respectively). Briefly, VLPs were coated in phosphatebuffered saline $(0.5 \mu \mathrm{g} / \mathrm{ml})$ on 96 -well polystyrene plates (Costar, Corning, NY, USA). Twofold serial dilutions of serum samples, starting at 1:100, were incubated on blocked plates for $1 \mathrm{~h}$ at $37^{\circ} \mathrm{C}$. Bound antibodies of serially diluted sera were detected with goat anti-human IgG-HRP (Invitrogen, CA, USA) followed by $o$-phenylenediamine dihydrochloride (OPD) substrate (Sigma-Aldrich, MO, USA). Optical density (OD) was measured, and a mean OD $\geq 0.100$ was considered positive. End-point titer was expressed as a reciprocal of final serum dilution having positive OD. Seroconversion was defined as at least fourfold increase in successive serum end-point titer. Serum antibodies able to block binding of GI.3 and GII.4 VLPs to HBGAs in human saliva and therefore potentially neutralize the virus were tested in blocking assay as previously described [10]. Briefly, 96-well plates were coated with type A saliva from a secretor-positive adult at 1:3000 dilution. Serially, twofold diluted sera (starting dilution 1:50) preincubated with GI.3 or GII.4 VLPs $(0.1 \mu \mathrm{g} / \mathrm{ml})$ for $1 \mathrm{~h}$ at $37{ }^{\circ} \mathrm{C}$ were added to the plates. VLPs without serum were used as maximum binding controls. Bound VLPs were detected with NoV genotype-specific mouse sera and anti-mouse IgG-HRP (Sigma-Aldrich) and OPD substrate. Blocking index (\%) was calculated as $100 \%$ $-[(O D$ wells with VLP serum mix/OD wells without serum; maximum binding $) \times 100]$. Blocking titer 50 (BT50) was determined as the reciprocal of the final serum dilution that blocked at least $50 \%$ of VLPs binding to the HBGA.

\section{Results}

Four different NoV infections, three with GII (GII.6, GII.4, and GII.2) and one with GI (GI.3) NoVs, were detected by RTPCR during a period of 15 months (Table 1). The child acquired febrile primary infection with GII.6 already at 4 months indicating that maternal antibodies although present in cord blood (end-point titer 800 to GI.3 and 3200 to GII.4, respectively) did not protect the child from NoV infection (Table 1 and Fig. 1). However, the cord blood antibodies completely lacked blocking potential of both VLPs (Fig. 1). Following the first infection, IgG seroconversion to GI.3 and GII.4 was detected at 6 months (Table 1 and Fig. 1). Although the levels of antibodies pertained until 12 months of age, they did not confer protection from a subsequent infection with GI.3 NoV at 13 months of age, and even though GII.4-specific antibodies detected at 12 month at a serum dilution 1:50 blocked $98 \%$ of GII.4 VLPs binding to the HBGA receptor/s (Fig. 1), they did not protect the child from acquiring GII.4 infection at 15 months of age (Table 1). Clinically, the child experienced a prolonged diarrhea for a period of 3-4 weeks at the age of 13-14 months. During that period, the child might have experienced the two sequential infections with GI.3 and GII.4 NoVs. After the infections with GI.3 and GII.4, serum antibody levels to both VLPs measured at 18 months increased 16 
Table 1 Detection of norovirus in stool samples and GI.3- and GII.4-specific antibodies in serum samples of a child from 0 to 25 months of age

\begin{tabular}{|c|c|c|c|c|c|}
\hline \multirow{2}{*}{$\begin{array}{l}\text { Age } \\
\text { (month) }\end{array}$} & \multirow{2}{*}{$\begin{array}{l}\text { Stool } \\
\text { collection }\end{array}$} & \multirow{2}{*}{$\begin{array}{l}\text { Serum } \\
\text { collection }\end{array}$} & \multirow{2}{*}{$\begin{array}{l}\text { RT-PCR } \\
\text { (stool samples) }\end{array}$} & \multicolumn{2}{|c|}{ Serum IgG ELISA } \\
\hline & & & & GI.3-specific & GII.4-specific \\
\hline 0 (cord blood) & No & Yes & & + & + \\
\hline 3 & No & Yes & & + & + \\
\hline 4 & Yes & No & GII.6 & & \\
\hline 5 & Yes & No & - & & \\
\hline 6 & Yes & Yes & - & ++ & ++ \\
\hline 7 & Yes & No & - & & \\
\hline 8 & Yes & No & - & & \\
\hline 10 & Yes & No & - & & \\
\hline 11 & Yes & No & - & & \\
\hline 12 & No & Yes & & + & + \\
\hline 13 & Yes & No & GI.3 & & \\
\hline 14 & Yes & No & - & & \\
\hline 15 & Yes & No & GII.4 & & \\
\hline 16 & Yes & No & - & & \\
\hline 17 & Yes & No & - & & \\
\hline 18 & No & Yes & & ++ & ++ \\
\hline 19 & Yes & No & GII.2 & & \\
\hline 25 & No & Yes & & + & + \\
\hline
\end{tabular}

- negative, + positive, ++ indicates fourfold increase in GI.3- and GII.4-specific end-point titer times (end-point titers 51,200 and 102,400, respectively) compared to the pre-infection titers at 12 months (end-point titers 3200 and 6400) (Fig. 1). The high antibody level to GII.4 genotype (end-point titer 102,400 with $97 \%$ blocking) did not prevent further infection with heterologous GII. $2 \mathrm{NoV}$ genotype already in the following month at the age of 19 months (Table 1 and Fig. 1), when the child again had typical clinical symptoms of gastroenteritis. These results
Fig. 1 Norovirus-specific serum IgG antibodies in a child from 0 to 25 months of age. Serum samples collected at $0,3,6,12,18$, and 25 months were tested for GI.3and GII.4-specific antibodies in ELISA and blocking assays. Endpoint titer is expressed as a reciprocal of final serum dilution giving an $\mathrm{OD} \geq 0.100$. Blocking index $(\%)$ is shown for serum dilutions 1:50. Blocking titer 50 (BT50), reciprocal of the final serum dilution with $50 \%$ blocking activity. Approximate time points of norovirus infections are indicated by arrows. $G E$ stands for gastroenteritis symptoms reported

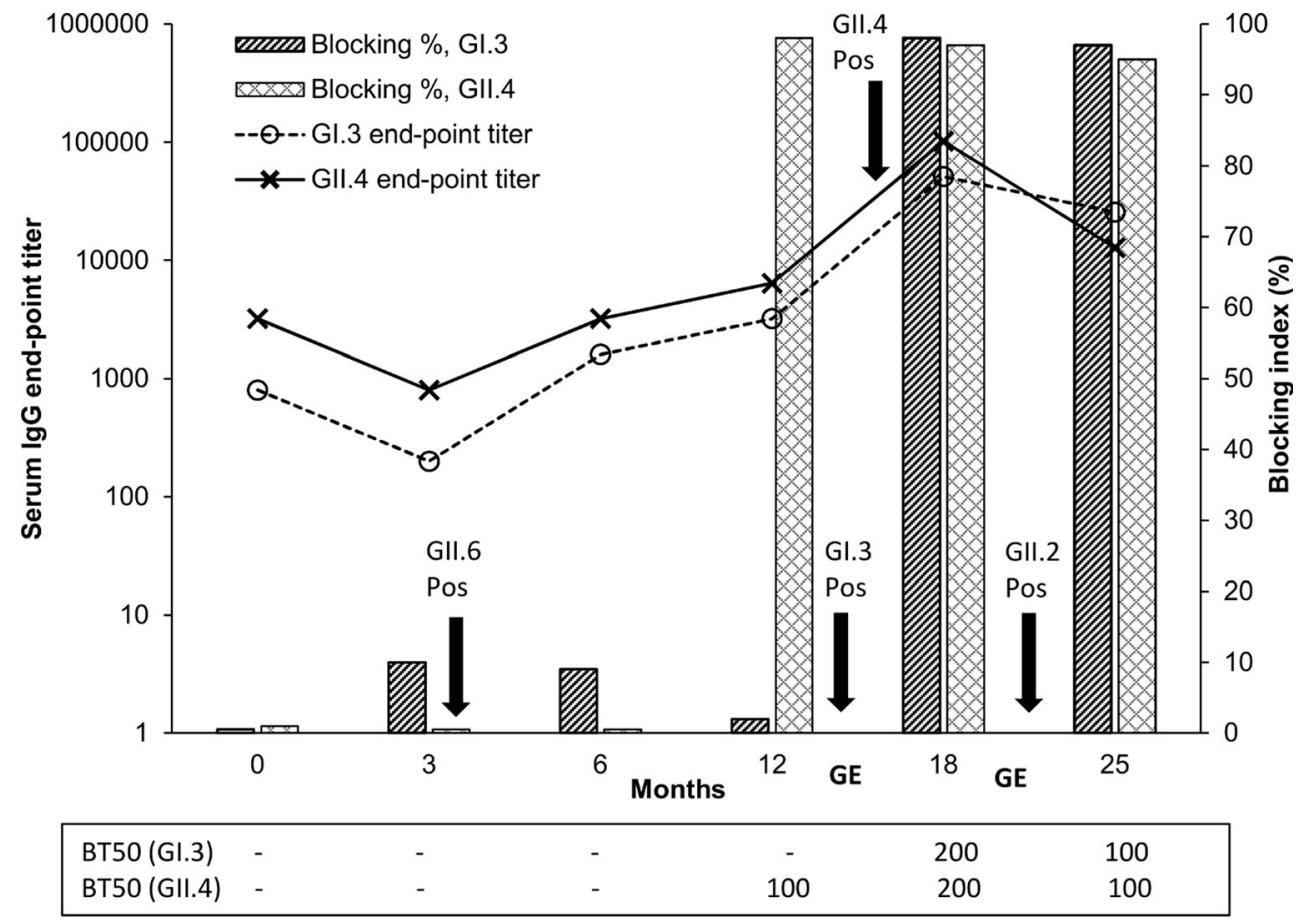


show complete lack of cross-protection between the GII NoVs. In 7 months' time (from 18-25 months), the child had retained only a half of GI.3 (end-point titer 25,600) and $1 / 8$ of GII.4-specific antibodies (end-point titer 12,800) in the serum (Fig. 1).

\section{Discussion}

Our study shows that a child can acquire as many as four consecutive NoV infections before the age of 2 years. Upon primary infection with GII.6 at 4 months, the child presented fever, but as there were no signs of vomiting or diarrhea, the infection was probably mild or asymptomatic, as recently reported [3]. Maternal antibodies present prior to the infection might have protected from severe disease but not the infection. A seroconversion to GII.4 was detected after the primary infection already at 6 months, but increase in blocking antibodies to GII.4 was detected at 12 months, suggesting that heterologous blocking antibodies may take longer time to develop. Although the child generated remarkable homologous serum antibody titer (GII.4-specific end-point titer 102,400, respectively) with high blocking activity (BT50 200), the immunity was not cross-protective and the child remained prone to infections with new GII.2 NoV genotype. The results presented here are in contrast to the findings observed in rotavirus infections, where protective antibody titers were achieved after two consecutive symptomatic or asymptomatic rotavirus infections in children less than 2 years of age [11]. The results in the present study suggest that NoV protective immunity in young children is type-specific. However, further studies in large pediatric populations are needed to address the magnitude, specificity, and duration of immune responses required for protection to $\mathrm{NoV}$ infection in young children. As children up to 2 years of age are highly vulnerable to infection and severe medically attended gastroenteritis, NoV vaccination of this target population is needed [12].

Acknowledgments We thank the personnel of the Vaccine Research Center and Virology Department at the University of Tampere for the technical assistance and the DIPP Study personnel at the Department of Pediatrics, University of Oulu, for the acquisition of the clinical samples.

\section{Compliance with ethical standards}

Funding This study was financially partly supported by Sigrid Juselius Foundation, Oulu University Hospital Research Funds, and Juvenile Diabetes Research Foundation. There was no other external funding received for this study.

Conflict of interest All authors declare that they have no competing interests.
Ethical approval All procedures performed in the studies involving human participants were in accordance with the ethical standards of the institutional and/or national research committee and with the 1964 Helsinki declaration and its later amendments or comparable ethical standards.

Informed consent Informed consent was obtained from the parents or legal guardians of all individual participants included in the study.

Authors' contributions Dr. V. Blazevic is the head of the laboratory of Vaccine Research Center, who designed this study, interpreted the results, and was the main author of this study. Dr. M. Malm was responsible for the immunological laboratory analysis and processing the data. M. Salminen was responsible for genotyping the noroviruses from the stool samples. S. Oikarinen coordinated the processing of DIPP biobank samples for virus analyses and was responsible for sample maintenance. Professor of Virology H. Hyöty, one principal investigator of the DIPP Study, and Dr. T. Vesikari, MD, the director of the Vaccine Research Center, critically reviewed the manuscript. Professor R. Veijola, MD, is one principal investigator of the DIPP Study and was responsible for the recruitment of the study subject and provided the samples and the data on clinical symptoms. All authors participated in writing and critical review and revision of the manuscript and approved the final manuscript as submitted.

Open Access This article is distributed under the terms of the Creative Commons Attribution 4.0 International License (http:// creativecommons.org/licenses/by/4.0/), which permits unrestricted use, distribution, and reproduction in any medium, provided you give appropriate credit to the original author(s) and the source, provide a link to the Creative Commons license, and indicate if changes were made.

\section{References}

1. Patel MM, Widdowson MA, Glass RI, Akazawa K, Vinje J, Parashar UD (2008) Systematic literature review of role of noroviruses in sporadic gastroenteritis. Emerg Infect Dis 14: 1224-1231

2. Kroneman A, Vega E, Vennema H, Vinje J, White PA, Hansman G, Green K, Martella V, Katayama K, Koopmans M (2013) Proposal for a unified norovirus nomenclature and genotyping. Arch Virol 158:2059-2068

3. Saito M, Goel-Apaza S, Espetia S, Velasquez D, Cabrera L, Loli S, Crabtree JE, Black RE, Kosek M, Checkley W, Zimic M, Bern C, Cama V, Gilman RH, Norovirus Working Group in Peru (2014) Multiple norovirus infections in a birth cohort in a Peruvian Periurban community. Clin Infect Dis 58:483-491

4. Sakon N, Yamazaki K, Nakata K, Kanbayashi D, Yoda T, Mantani M, Kase T, Takahashi K, Komano J (2014) Impact of genotypespecific herd immunity on the circulatory dynamism of norovirus: a 10 -year longitudinal study of viral acute gastroenteritis. J Infect Dis 211:879-88

5. Parra GI, Green KY (2014) Sequential gastroenteritis episodes caused by 2 norovirus genotypes. Emerg Infect Dis 20:1016-1018

6. Reeck A, Kavanagh O, Estes MK, Opekun AR, Gilger MA, Graham DY, Atmar RL (2010) Serological correlate of protection against norovirus-induced gastroenteritis. J Infect Dis 202:12121218

7. Nanto-Salonen K, Kupila A, Simell S, Siljander H, Salonsaari T, Hekkala A, Korhonen S, Erkkola R, Sipila J, Haavisto L, Siltala M, Tuominen J, Hakalax J, Hyoty H, Ilonen J, Veijola R, Simell T, 
Knip M, Simell O (2008) Nasal insulin to prevent type 1 diabetes in children with HLA genotypes and autoantibodies conferring increased risk of disease: a double-blind, randomised controlled trial. Lancet 372:1746-1755

8. Puustinen L, Blazevic V, Salminen M, Hamalainen M, Rasanen S, Vesikari T (2011) Noroviruses as a major cause of acute gastroenteritis in children in Finland, 2009-2010. Scand J Infect Dis 43: 804-808

9. Blazevic V, Lappalainen S, Nurminen K, Huhti L, Vesikari T (2011) Norovirus VLPs and rotavirus VP6 protein as combined vaccine for childhood gastroenteritis. Vaccine 29:8126-8133
10. Malm M, Uusi-Kerttula H, Vesikari T, Blazevic V (2014) High serum levels of norovirus genotype-specific blocking antibodies correlate with protection from infection in children. J Infect Dis 210:1755-1762

11. Velazquez FR, Matson DO, Guerrero ML, Shults J, Calva JJ, Morrow AL, Glass RI, Pickering LK, Ruiz-Palacios GM (2000) Serum antibody as a marker of protection against natural rotavirus infection and disease. J Infect Dis 182: $1602-1609$

12. Vesikari T, Blazevic V (2014) Norovirus vaccine: one step closer. J Infect Dis 211:853-5 